\title{
Uso do silicato de potássio no controle de oídio em mudas de Eucalyptus benthamii
}

\author{
Bruno Schultz¹, Karen Christiane Bora1, Antônio Carlos Nogueira1 , Celso Garcia Auer²
}

1 Universidade Federal do Paraná , Av. Pref. Lothário Meissner, 900, CEP 80210-170, Curitiba, PR, Brasil

${ }^{2}$ Embrapa Florestas, Estrada da Ribeira, Km 111, CP 319, CEP 83411-000,Colombo, PR, Brasil

\section{"Autor correspondente:}

schultz.florestal@gmail.com

Termos para indexação:

Silício

Resistência

Oidium eucalypti

Index terms:

Silicon

Resistance

Oidium eucalypti

Histórico do artigo:

Recebido em 30 maio 2011

Aprovado em 06 fev 2012

Publicado em 30 mar 2012

doi: 10.4336/2012.pfb.32.69.93
Resumo - Avaliou-se a efetividade do silicato de potássio $\left(\mathrm{K}_{2} \mathrm{SiO}_{3}\right)$ no controle de oídio em mudas de Eucalyptus benthamii. Quatro tratamentos foram testados: pulverização de $\mathrm{K}_{2} \mathrm{SiO}_{3}\left(4 \mathrm{~mL} \mathrm{~L}^{-1}\right)$ por sete dias, pulverização de $\mathrm{K}_{2} \mathrm{SiO}_{3}\left(4 \mathrm{~mL} \mathrm{~L}^{-1}\right)$ por 14 dias, pulverização do fungicida epoxiconazole + piraclostrobina $\left(6 \mathrm{~mL} \mathrm{~L}^{-1}\right)$ por 14 dias e pulverização de água ultrapurificada por 7 dias. Dez mudas com 90 dias de idade foram utilizadas por parcela em três blocos ao acaso. A inoculação foi feita pincelando-se esporos de Oidium eucalypti, retirados de mudas de E. benthamii já infectadas, sobre aspartes superiores de mudas sadias. Aos 150 dias, avaliou-se a severidade da doença e determinou-se a massa fresca (MF) e a massa seca (MS) da parte aérea. Mediu-se o diâmetro do coleto (DC) e altura (H) das mudas aos 120 e 150 dias. Não houve diferenças significativas no incremento em altura das mudas, na relação H/DC e MS. A pulverização de silicato de potássio aos 14 dias apresentou os melhores resultados no incremento do colo, no controle da doença e na diferença entre MS e $\mathrm{MF}(\mathrm{p}<0,05)$. $\mathrm{O}$ uso de silicato de potássio em intervalos de 14 dias pode ser uma forma de controle do oídio, favorecendo o crescimento da muda de $E$. benthamii.

\section{Use of potassium silicate for powdery mildew control in Eucalyptus benthamii seedlings}

\begin{abstract}
The effectiveness of potassium silicate $\left(\mathrm{K}_{2} \mathrm{SiO}_{3}\right)$ to control powdery mildew was evaluated in Eucalyptus benthamii seedlings. Four treatments were applied: sprays of $\mathrm{K}_{2} \mathrm{SiO}_{3}\left(4 \mathrm{~mL} \mathrm{~L}^{-1}\right)$ for 7 days, $\mathrm{K}_{2} \mathrm{SiO}_{3}\left(4 \mathrm{~mL} \mathrm{~L}^{-1}\right)$ for 14 days, fungicide epoxiconazole + pyraclostrobin $\left(6 \mathrm{~mL} \mathrm{~L}^{-1}\right)$ for 14 days and ultrapurified water for 7 days. The experiment consisted of a randomized complete block design with three replicates, each with 10 seedlings with 90 days old per plot. Inoculation was done by brushing spores of Oidium eucalypti, collected from infected $E$. benthamii seedlings, onto superior parts of healthy seedlings. It was measured the diameter of the root collar (DC) and height $(\mathrm{H})$ of the seedlings at 120 and 150 days. After 150 days, severity of disease, fresh mass (MF) and dry mass (MS) of aerial part were determined. No statistically significant differences were observed in height increment of the seedlings, in H/DC and MS. Sprays of potassium silicate at 14-days intervals showed the best results in the increase of the DC, in disease control and the difference between MS and MF ( $p$ $<0.05$ ). The use of potassium silicate at 14-days intervals can be a form of control of powdery mildew, favoring the seedling growth of E. benthamii.
\end{abstract}




\section{Introdução}

$\mathrm{Na}$ região Sul do Brasil, um aumento no plantio de espécies de eucalipto resistentes à geada tem sido constatado, notadamente em áreas tradicionais de plantios de Pinus (Paludzyszyn Filho \& Santos, 2005). A espécie Eucalyptus benthamii Maiden é a espécie mais promissora para localidades com frio intenso e estimase que no estado do Paraná existam cerca de 10 mil ha plantados. Sua importância aumenta quando é utilizado como base para formação de híbridos e clones comerciais resistentes ao frio (Remade, 2009).

A crescente demanda por mudas de E. benthamii estimula o acompanhamento dos fatores que influenciam seu desenvolvimento na fase de viveiro. Nesta fase devem ser monitoradas as doenças que causam danos e redução na produção e qualidade das mudas.

Dentre as principais doenças fúngicas do eucalipto no viveiro destaca-se o oídio causado pelo agente etiológico Oidium eucalypti (Santos et al., 2001). Esta doença tem sido verificada em mudas de E. benthamii, em várias regiões do Paraná e de Santa Catarina. Ocorre preferencialmente em casa de vegetação e minijardim clonal, com incidência em folhas e brotos jovens, o que causa encarquilhamento foliar e superbrotamento das plantas, acarretando em alguns casos a morte de mudas (Krugner \& Auer, 2005).

O controle desta doença nos viveiros de eucalipto pode ser feito com os mesmos fungicidas recomendados para espécies agrícolas, contudo seu uso não é permitido (Bizi et al., 2005). A periculosidade e toxicologia dos produtos químicos têm estimulado a diminuição da sua demanda e o aumento de pesquisas com o uso de medidas ou controle cultural, controle biológico, controle genético e o controle com produtos alternativos (Campanhola \& Bettiol, 2003). Bizi et al. (2008) estudando o controle do oídio sobre mudas de $E$. benthamii por meio de produtos alternativos obteve resultados positivos, ao utilizar leite de vaca e Lecanicillium sp.

Uma das alternativas no controle alternativo de doenças é a utilização do silício ( $\mathrm{Si}$ ) como agente indutor de resistência. O silício fornecido é um elemento bastante benéfico para o crescimento e desenvolvimento das plantas do ponto de vista fisiológico e metabólico. Além disso, aumenta a produção de biomassa de um grande número de plantas além de promover rigidez para suas estruturas (Epstein, 1999). O silicato de potássio é responsável pela ativação de mais de 60 enzimas e pela abertura das células guarda do estômato, o que favorece a turgidez destas células e mantêm a planta hidratada em períodos de déficit hídrico (Epstein \& Bloom, 2004).

O uso do silício tem se mostrado eficiente no controle de doenças fúngicas importantes em gramíneas, demonstrando que a aplicação na cultura do arroz pode reduzir a incidência de bruzone entre $17 \%$ e $31 \%$ (Datnoff et al., 2001). Além disso, contribui para o fortalecimento da planta e dificulta a penetração de hifas de fungos fitopatogênicos (Korndörfer et al., 2002). Com esta perspectiva, o objetivo deste trabalho foi avaliar, em condição de casa de vegetação, o efeito do silicato de potássio $\left(\mathrm{K}_{2} \mathrm{SiO}_{3}\right)$ no controle de oídio em mudas de $E$. benthamii e no crescimento destas mudas, e sua eficiência em relação ao fungicida comercialmente utilizado para controle de oídio.

\section{Material e métodos}

\section{Produção de mudas, inoculação e aplicação do silicato}

O ensaio foi realizado nos meses de outubro a dezembro de 2010, em casa de vegetação do Laboratório de Patologia Florestal da Embrapa Florestas, Colombo, PR. Foram utilizadas mudas de Eucalyptus benthamii com três meses de idade, formadas com sementes de Área Produtora de Sementes (APS), procedentes de viveiro comercial localizado no município de Guarapuava, PR. As mudas foram produzidas em tubetes de $50 \mathrm{~cm}^{3}$ preenchidos com substrato comercial a base de vermiculita e casca de pínus e adubação de base com osmote. Na casa de vegetação, as mudas foram acondicionadas em bandejas e mantidas com irrigação manual apenas molhando-se o substrato.

O fungo Oidium eucalypti foi inoculado por meio da raspagem superficial de folhas de mudas de $E$. benthamii já infectadas (apresentando sintomas e sinais visíveis do fungo), com o uso de um pincel pequeno. Nesta raspagem, os conídios do patógeno foram inoculados no terço superior das mudas sadias do ensaio.

As mudas foram alocadas em delineamento em blocos ao acaso com três blocos, dez plantas por parcela, e três tratamentos e uma testemunha. Os tratamentos foram: pulverização de silicato de potássio $\left(\mathrm{K}_{2} \mathrm{SiO}_{3}\right)$ a cada 7 dias; pulverização de silicato de potássio $\left(\mathrm{K}_{2} \mathrm{SiO}_{3}\right)$ a cada 14 dias; pulverização com epoxiconazol + piraclostrobina, a cada 14 dias (controle positivo). A testemunha foi feita pela pulverização de água 
ultrapurificada. Os tratamentos foram aplicados com um pulverizador manual de jardim.

A concentração de silicato de potássio utilizada foi de $4 \mathrm{~mL} \mathrm{~L}^{-1}$ de água ultrapurificada, enquanto que a concentração do fungicida epoxiconazole + piraclostrobina foi de $6 \mathrm{~mL} \mathrm{~L}^{-1}$ de água ultrapurificada. Os produtos foram pulverizados na parte abaxial e adaxial de todas as folhas até o ponto de escorrimento. Para a testemunha, utilizou-se somente água ultrapurificada, a cada 7 dias.

As mudas permaneceram por dois meses em casa de vegetação, sendo avaliadas aos 30 e 60 dias de permanência, totalizando 150 dias de idade. Ao final dos 150 dias, fez-se a avaliação da severidade do oídio nas mudas e a determinação do peso da matéria seca das mesmas.

\section{Avaliação de variáveis de crescimento das mudas}

Inicialmente, procedeu-se à medição do diâmetro do colo e a altura da parte aérea de todas as mudas. No período de dois meses de instalação, foram obtidos os dados de altura $(\mathrm{H})$ e diâmetro do colo (DC) das mudas e com isso foi obtido o incremento em diâmetro e altura parcial em cada idade (H1, H2, H3, DC1, DC2 E DC3) de cada muda. Além disso, o incremento em altura da parte aérea total (IPAT) e o incremento do diâmetro do colo (IDC) foram obtidos ao final do experimento. Outra variável utilizada com o objetivo de avaliar a qualidade da muda foi a relação H/DC.

Após a última medição, as mudas foram cortadas à altura do colo e colocadas em sacos de papel subdividas em tratamentos e blocos. Cada saco com 10 mudas foi pesado obtendo a massa fresca (MF). Após determinada a massa fresca, o material vegetal (aéreo e radicial) foi secado em estufa a $40{ }^{\circ} \mathrm{C}$, por 18 horas, até atingir peso constante, quando foi pesado em balança de precisão com aproximação de $0,01 \mathrm{~g}$ e determinada a massa seca (MS). O teor de água $\left(\mathrm{T}_{\mathrm{H} 2 \mathrm{O}}\right)$ das mudas foi calculado por meio da diferença entre a MF e MS.

\section{Avaliação da severidade da doença}

A severidade da doença foi quantificada por meio da escala de severidade proposta por Paz Lima et al. (2004) e adaptada por Bizi et al. (2005) descrita na Tabela 1. Pelo fato da doença ser mais intensa nas folhas mais novas, a análise da severidade dos sintomas e sinais foi realizada observando-se somente o terço superior de todas as mudas.
Tabela 1. Escala diagramática utilizada para avaliar a severidade do oídio em mudas de Eucalyptus benthamii.

\begin{tabular}{ccl}
\hline Nota & $\begin{array}{c}\text { Quantificação da } \\
\text { severidade }\end{array}$ & \multicolumn{1}{c}{ Sintomas visuais } \\
\hline 0 & Sem sintomas & Ausentes \\
1 & Leve & $\begin{array}{l}\text { Presença de micélio do fungo na } \\
\text { folha, sem esporulação. }\end{array}$ \\
2 & Média & $\begin{array}{l}\text { Esporulação sobre menos de } 50 \% \\
\text { da muda. }\end{array}$ \\
3 & Alta & $\begin{array}{l}\text { Esporulação sobre mais de } 50 \% \text { da } \\
\text { muda. }\end{array}$ \\
\hline 4 & Muito alta & $\begin{array}{l}\text { Deformação da folha; necrose, } \\
\text { enrolamento do primeiro par de } \\
\text { folhas e queda das folhas. }\end{array}$ \\
\hline
\end{tabular}

Fonte: Bizi et al. (2005).

\section{Análises estatísticas}

A análise estatística dos dados de crescimento das mudas e da severidade da doença foi realizada em planilha eletrônica, com $95 \%$ de confiança. O teste de Barttlet avaliou a homogeneidade das variâncias e, quando heterogêneas, os dados foram transformados para arcseno $\sqrt{\mathrm{P}} / 100$. Após o teste de Barttlet, as médias dos tratamentos foram analisadas por meio do teste de diferença mínima significativa (DMS) ao nível de 5\% de probabilidade (Oliver \& Boyd, 1925).

\section{Resultados e discussão}

\section{Avaliação de variáveis de crescimento das mudas}

O desenvolvimento das mudas de Eucalyptus benthamii foi parcialmente afetado pela aplicação de silicato de potássio. Pode-se observar que as variáveis: incremento da parte aérea total, massa fresca e relação $\mathrm{H} /$ DC não apresentaram diferenças significativas $(\mathrm{p}>0,05)$. Para o incremento do colo, severidade do oídio, massa fresca, massa seca e $\mathrm{T}_{\mathrm{H} 2 \mathrm{O}}$ (diferença entre massa fresca e massa seca), as diferenças foram significativas ( $\mathrm{p}<$ $0,05)$, conforme podem ser visualizados na Tabela 2.

Dentro do período de avaliação do ensaio, o incremento da parte aérea total (IPAT) das mudas não diferiu significativamente entre os tratamentos (Tabela 2). Gomes et al. (2003) estudando mudas de E. grandis e diferentes taxas de adubação (NPK) verificaram incremento médio em altura das mudas de $5,78 \mathrm{~cm}$, dos 90 aos 120 dias de avaliação. As mudas de E. benthamii, neste mesmo período, apresentaram incremento médio de 4,8 cm (Tabela 3 ). 
O incremento do diâmetro do coleto (IC) das mudas entre 90 e 150 dias foi significativo para a aplicação de $\mathrm{K}_{2} \mathrm{SiO}_{3}$. O uso de $\mathrm{K}_{2} \mathrm{SiO}_{3}$ aplicado aos sete e 14 dias propiciou melhores resultados em incremento de colo que os demais tratamentos (Tabelas 2 e 3 ). A presença do potássio em níveis crescentes, em experimento realizado por Carneiro (1995), proporcionou um maior engrossamento, endurecimento das mudas e aumento da resistência às condições adversas do meio. Gomes et al. (2003), ao avaliarem o crescimento de mudas de $E$. grandis, no período de 90 aos 120 dias, verificaram IC de 0,124 mm, inferior aos valores de IC para o T1, T2 e T3 neste período (Tabela 3). Os resultados sugerem que a aplicação de potássio via foliar em mudas de $E$. benthamii pode influenciar o incremento do colo.

Tabela 2. Efeito da aplicação de $\mathrm{K}_{2} \mathrm{SiO}_{3}$ e piraclostrobina mais epoxiconazole sobre algumas variáveis do crescimento de mudas de E. benthamii e na severidade de oídio.

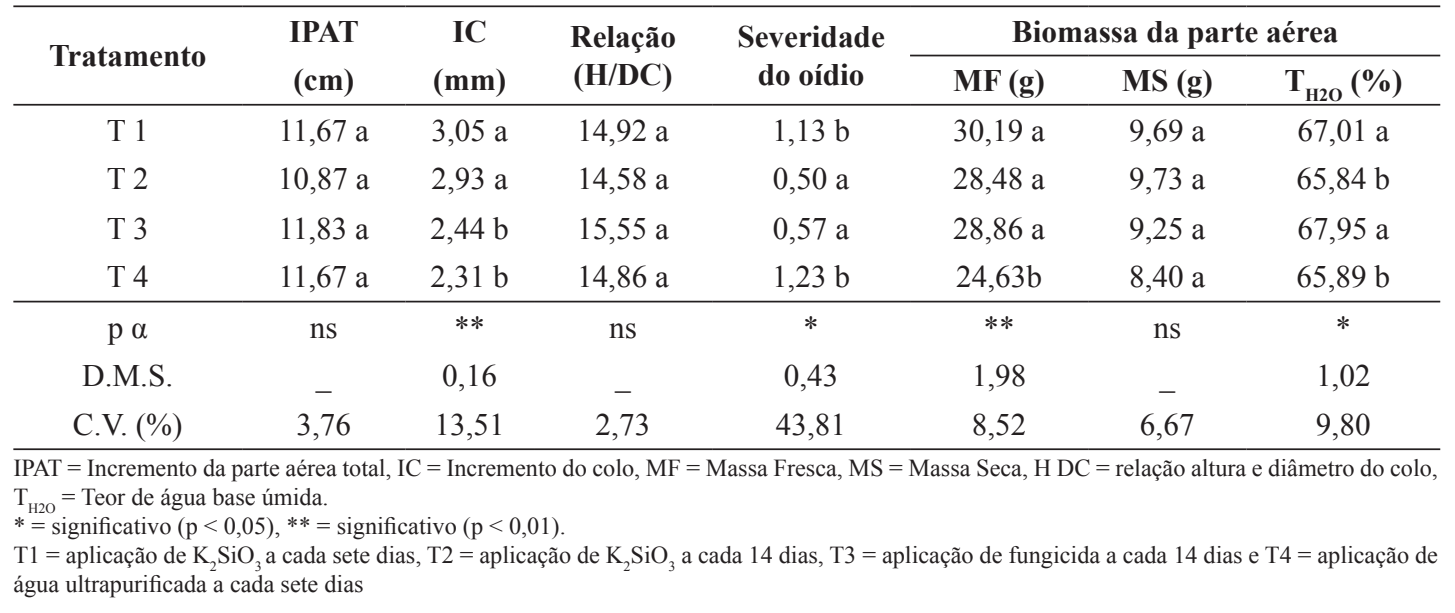

Tabela 3. Efeito da aplicação de $\mathrm{K}_{2} \mathrm{SiO}_{3}$ e piraclostrobina mais epoxiconazole sobre a altura, diâmetro do coleto e incrementos médios da parte aérea e do coleto das mudas de mudas de Eucalyptus benthamii aos 90, 120 e 150 dias de idade.

\begin{tabular}{|c|c|c|c|c|c|c|c|c|c|c|c|c|}
\hline \multirow{3}{*}{ Tratamentos } & H1 & DC1 & H2 & DC2 & H3 & DC3 & IPA1 & IC1 & IPA2 & IC2 & IPAT & ICT \\
\hline & \multicolumn{2}{|c|}{90 dias } & \multicolumn{2}{|c|}{120 dias } & \multicolumn{2}{|c|}{150 dias } & \multicolumn{2}{|c|}{$\begin{array}{c}(90-120) \\
\text { dias }\end{array}$} & \multicolumn{2}{|c|}{$\begin{array}{c}(120-150) \\
\text { dias }\end{array}$} & \multicolumn{2}{|c|}{$\begin{array}{c}(150-190) \\
\text { dias }\end{array}$} \\
\hline & cm & $\mathbf{m m}$ & cm & $\mathbf{m m}$ & $\mathbf{c m}$ & $\mathbf{m m}$ & $\mathrm{cm}$ & $\mathbf{c m}$ & cm & $\mathbf{c m}$ & $\mathrm{cm}$ & $\mathbf{c m}$ \\
\hline T 1 & 32,2 & 2,63 & 36,8 & 2,71 & 43,8 & 2,94 & 4,66 & 0,19 & 7,00 & 0,19 & 11,7 & 0,30 \\
\hline Т 2 & 33,1 & 2,68 & 37,4 & 2,38 & 44,0 & 2,98 & 4,30 & 0,14 & 6,57 & 0,15 & 10,9 & 0,29 \\
\hline T 3 & 30,9 & 2,59 & 36,2 & 2,81 & 42,6 & 2,84 & 5,30 & 0,22 & 6,37 & 0,03 & 11,7 & 0,24 \\
\hline $\mathrm{T} 4$ & 32,1 & 2,63 & 37,1 & 2,68 & 43,6 & 2,86 & 4,92 & 0,05 & 6,59 & 0,18 & 11,5 & 0,23 \\
\hline Média & 32,0 & 2,64 & 36,9 & 2,77 & 43,5 & 2,90 & 4,80 & 0,13 & 6,63 & 0,14 & 11,4 & 0,26 \\
\hline C.V. $(\%)$ & 2,84 & 1,47 & 1,39 & 2,38 & 1,47 & 2,26 & 8,80 & 5,19 & 3,98 & 5,55 & 3,31 & 1,35 \\
\hline
\end{tabular}

Trigueiro e Guerrini (2003), avaliando o crescimento de mudas de E. grandis, verificaram DC aos 120 dias de $2,57 \mathrm{~mm}$. Para a espécie E. viminalis aos 106 dias foi observado DC médio das mudas de 1,51 mm (Bonnet, 2001). Apesar de esses trabalhos terem sido realizados sem a presença de oídio sobre as mudas, os diâmetros de coleto relatados foram inferiores ao diâmetro do coleto das mudas de E. benthamii aos 120 dias, que foi de 2,77 mm (Tabela 3).

Para a relação H/DC, as diferentes pulverizações com $\mathrm{K}_{2} \mathrm{SiO}_{3}$ não apresentaram diferença significativa. Com base nestes resultados, a contribuição do $\mathrm{K}_{2} \mathrm{SiO}_{3}$ 
para as mudas foi a mesma obtida pela testemunha (Tabela 2). A variável H/DC, segundo Carneiro (1995), exprime o equilíbrio de crescimento das mudas do viveiro, pois conjuga duas características em apenas um índice que deve se situar entre 5,4 e 8,1, e neste estudo os valores estiveram acima desta faixa. De acordo com Kratz (2011), pode-se verificar que o H/DC encontrado para o gênero Eucalyptus é superior ao proposto por Carneiro (1995). Este autor obteve H/DC de mudas de $E$. benthamii entre 11,05 à 13,14 , valores próximos porém inferiores aos encontrados neste trabalho (Tabela 2). Bonnet (2001) observou relações H/DC entre 12,9 a 13 para mudas de E. viminalis, utilizando diferentes substratos na composição das mudas. Para mudas de E. grandis, os índices observados foram de 10,7 a 13 (Trigueiro \& Guerrini, 2003). Gomes et al. (2002), reforçam tal afirmação, pois o $\mathrm{H} / \mathrm{DC}$ apresentou $0,66 \%$ de contribuição para avaliar a qualidade de mudas de $E$. grandis, sendo desta forma dispensável.

Observou-se aumento de massa fresca (MF) e $\mathrm{T}_{\mathrm{H} 2 \mathrm{O}}$ quando se usou $\mathrm{K}_{2} \mathrm{SiO}_{3}$ (Tabela 2). Segundo Epstein (1999), a MF das plantas aumenta quando se aplica potássio em quantidades adequadas, pelo aumento na quantidade de água dentro das células, mantendo a planta hidratada por longos períodos. No tratamento com fungicida, a MF e $\mathrm{T}_{\mathrm{H} 2 \mathrm{O}}$ foi igual à aplicação de silicato de potássio. Esse efeito pode ser atribuído às alterações fisiológicas ocasionadas pelo fungicida, que favorecem o crescimento e desenvolvimento das plantas (Grossmann \& Retzlaff, 1997).

A MS não foi significativamente afetada pelos tratamentos, apesar de que os menores valores médios obtidos foram verificados no tratamento testemunha, em que se aplicou apenas água e os maiores valores médios foram obtidos com uso de fungicida (Tabela 2).

\section{Avaliação da severidade da doença}

Houve redução significativa no controle de oídio com a pulverização de silicato de potássio em intervalos de 14 dias, a qual não diferiu do fungicida epoxiconazol + piraclostrobina (Tabela 2). Quando o silício é suplementado, a resistência das plantas às doenças pode ser aumentada por meio da formação de barreiras mecânicas e/ou pela alteração das respostas químicas da planta ao ataque do parasita, aumentando a síntese de toxinas que podem agir como substâncias inibidoras ou repelentes. Além da barreira física, devido à acumulação na epiderme das folhas, o silício ativa genes envolvidos na produção de compostos secundários do metabolismo, como os polifenóis e enzimas relacionadas com os mecanismos de defesa das plantas. Deste modo, o aumento de silício nos tecidos vegetais faz com que a resistência da planta ao ataque do fungo patogênico aumente, devido à produção suplementar de toxinas que podem agir como substâncias inibidoras do patógeno (Lima Filho, 2005).

A pulverização do silicato de potássio realizada a cada sete dias não diferiu significativamente para a água ultrapurificada, correspondendo em maiores graus de severidade (Tabela 2). Para a pulverização aos sete dias, a maior severidade do oídio pode ser explicada por uma maior quantidade de potássio disponível para a absorção foliar pelas mudas. Segundo Marschner (1995), elevadas quantidades de $\mathrm{K}$ nos tecidos vegetais pode interferir na translocação e na disponibilidade fisiológica do $\mathrm{Mg}$ e do $\mathrm{Ca}$, resultando em desordens metabólicas e levando a maior severidade de doenças. Resultados similares foram encontrados por Pozza et al. (2001), Garcia Junior et al. (2003) e Amaral et al. (2008), trabalhando com cultivos agrícolas em casa de vegetação.

Observa-se que o uso de fungicida e silício propiciou às mudas maior MF (Figura 1A). O silício forma barreiras mecânicas incluindo mudanças na anatomia, como células epidérmicas mais grossas e um grau maior de lignificação e/ou silicificação (acúmulo de silício) de acordo com Lima Filho (2005).

Também se observou que para o maior grau de severidade nas folhas do hospedeiro, menor foi sua MF e $\mathrm{T}_{\mathrm{H} 2 \mathrm{O}}$ (Figura 1A). $\mathrm{O}$ ataque do patógeno dá origem a folhas de limbo enrugado, afilado e geralmente com uma metade mais estreita do que a outra, fatores que interferem na qualidade (Krugner \& Auer, 2005; Bizi et al., 2005) e devem ter reduzido a massa fresca das mudas. Porém, o oídio parece não ter influenciado a MS (Figura 1A), variável importante que determina a qualidade final da muda, pois está associada com a rusticidade. De acordo com a Figura 1B, a severidade do oídio também não teria influenciado o IPAT e H/DC. 

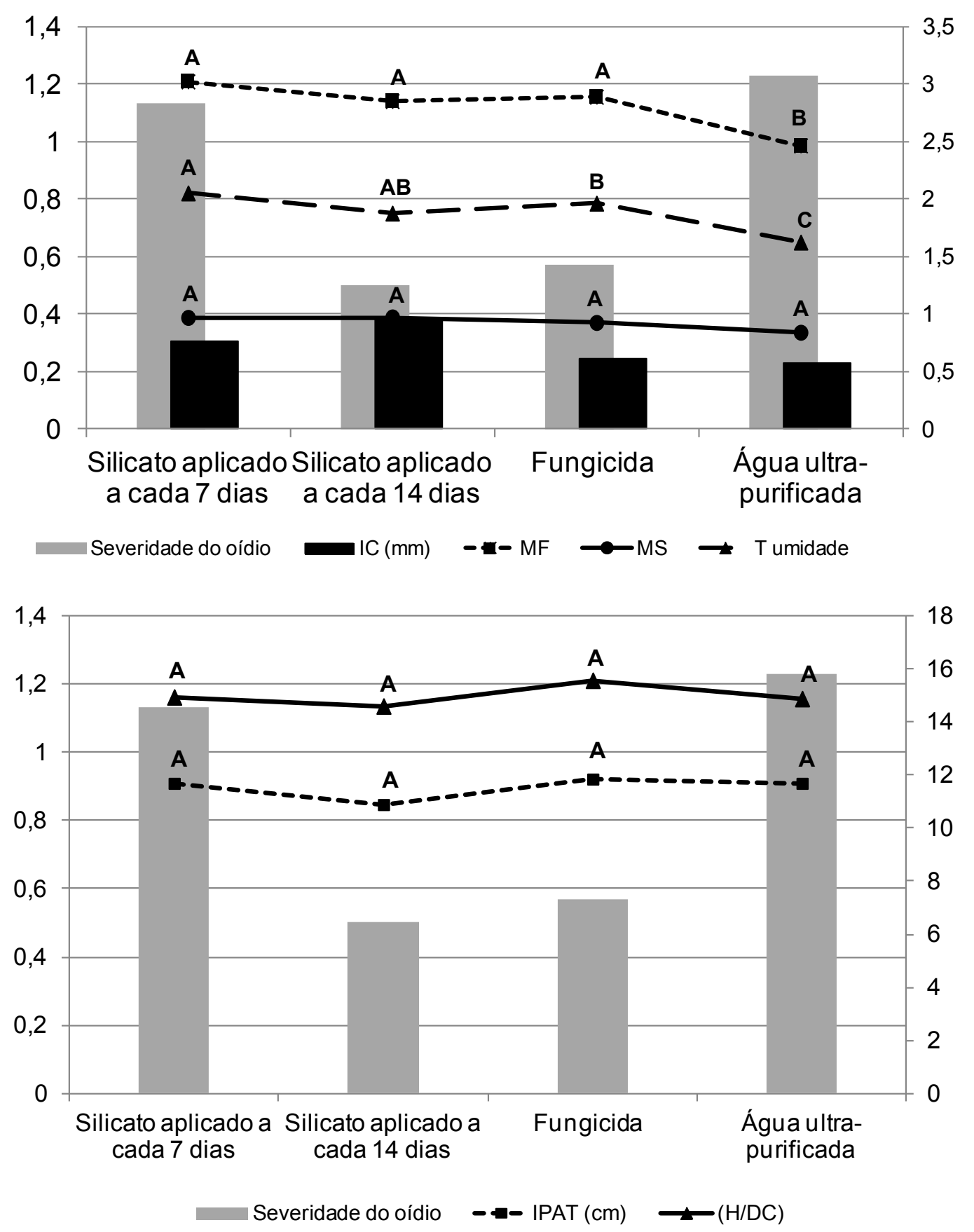

Figura 1. Resposta do uso de silicato de potássio sobre a severidade do oídio e sobre o desenvolvimento das mudas de Eucalyptus benthamii. A) Comparando-se severidade com IC (incremento do colo), MF (massa fresca), MS (massa seca) e MF-MS ( $\mathrm{T}_{\mathrm{H} 2 \mathrm{O}}=$ teor de água); B) Comparando-se severidade com IPAT (incremento da parte aérea total) e H/DC (relação altura e diâmetro do colo). 


\section{Conclusão}

Os melhores tratamentos para o controle do oídio foram: pulverização de silicato de potássio e do fungicida epoxiconazol + piraclostrobina, em intervalos de aplicação de 14 dias.

\section{Referências}

AMARAL, D. R.; RESENDE, M. L. V.; RIBEIRO JÚNIOR, P. M.; BOREL, J. C.; MAC LEOD, R. E. O.; PÁDUA, M. A. Silicato de potássio na proteção do cafeeiro contra Cercospora coffeicola. Tropical Plant Pathology, Lavras, MG, v. 63, n. 6, p. 425-431, 2008.

BIZI, R. M.; GRIGOLETTI JUNIOR, A.; AUER, C. G. Seleção de fungicidas para controle de oídio em eucalipto. Boletim de Pesquisa Florestal, Colombo, n. 51, p. 100-107, 2005.

BIZI, R. M.; GRIGOLETTI JUNIOR, A.; AUER, C. G.; MAY-DE MIO, L. L. Produtos alternativos no controle do oídio em mudas de eucalipto. Summa Phytopathologica, Jaguariuna, v. 34, n. 1, p. 144-148, 2008.

BONNET, B. R. P. Produção de mudas de Eucalyptus viminalis Lambill. (Myrtaceae), Schinus terebinthifolius Raddi (Anacardiaceae) e Mimosa scabrella Benth. (Mimosaceae) em substrato com lodo de esgoto anaeróbio digerido alcalinizado e compostado. 2001. 135 f. Dissertação (Mestrado em Engenharia Florestal) - Universidade Federal do Paraná, Curitiba.

CAMPANHOLA, C.; BETTIOL, W. Métodos alternativos de controle fitossanitário. Jaguariúna: Embrapa Meio Ambiente, 2003. 279 p.

CARNEIRO, J. G. A. Produção e controle de qualidade de mudas florestais. Curitiba: UFPR/FUPEF, 1995. $451 \mathrm{p}$.

DATNOFF, L. E.; SNYDER, G. H.; KORNDÖRFER, G. H. Silicon in Agriculture. Amsterdam: Elsevier, 2001. 403 p.

EPSTEIN, E. Silicon. Annual Review of Plant Physiology and Plant Molecular Biology, Palo Alto, v. 50, p. 641-664, 1999.

EPSTEIN, E.; BLOOM, A. J. Mineral nutrition of plants. 2nd. ed. Sunderland: Sinauer Associates, 2004. 402 p.

GARCIA JUNIOR, D.; POZZA, E. A.; POZZA, A. A.; SOUZA, P. E.; CARVALHO, J. G.; BALIERO, A. C. Incidência e severidade da cercosporiose do cafeeiro em função do suprimento de potássio e cálcio em solução nutritiva. Fitopatologia Brasileira, Brasília, DF, v. 28, p. 286-291, 2003.

GOMES, J. M.; COUTO, L.; LEITE, H. G.; XAVIER, A.; GARCIA, S. L. R. Crescimento de mudas de Eucalyptus grandis em diferentes tamanho de tubetes e fertilização N-P-K. Revista Árvore, Viçosa, MG, v. 27, n. 2, p. 113-127, 2003.

GOMES, J. M.; COUTO, L.; LEITE, H. G.; XAVIER, A. GARCIA, S. L. R. Parâmetros morfológicos na avaliação da qualidade de mudas de Eucalyptus grandis. Revista Árvore, Viçosa, MG, v. 26, n. 6, p. 655-664, 2002.
GROSSMANN, K.; RETZLAFF, G. Bioregulatory effects of the funcidal strobirin kresoxim methyl in wheat (Triticum aestivum L.) Pesticide Science, Oxford, v. 50, p. 11-20, 1997.

KORNDÖRFER, G. H.; PEREIRA, H. S.; CAMARGO, M. S. Silicatos de cálcio e magnésio na agricultura. 2.ed. Uberlândia: GPSi/ICIAG/UFU, 2002. 124 p. (Boletim Técnico, 1).

KRATZ, D. Substratos renováveis para produção de mudas de Eucalyptus benthami Maiden et Cambage e Mimosa scabrella Benth. 2011. 118 f. Dissertação (Mestrado em Ciência Florestal) - Universidade Federal do Paraná, Curitiba.

KRUGNER, T. L.; AUER, C. G. Doenças dos eucaliptos. In: KIMATI, H.; AMORIM, L.; REZENDE, J. A. M.; BERGAMIN FILHO, A.; CAMARGO, L. E. A. (Ed.). Manual de fitopatologia: doenças das plantas cultivadas. 4. ed. São Paulo: Agronômica Ceres, 2005. p. 319-332.

LIMA FILHO, O. F. de. O silício e a resistência das plantas ao ataque de fungos patogênicos. 26 set. 2005. Disponível em: http:/www.embrapa.br/imprensa/artigos/2005/ artigo.2005-09-26.3380213476>. Acesso em: 23 mar. 2011.

MARSCHNER, H. Mineral nutrition of higher plants. 2nd. ed. New York: Academic Press, 1995. 902 p.

OLIVER, B.; BOYD, W. Statistical methods for research workers. London: Elsevier, 1925. 129 p.

PAZ LIMA, M. L.; LOPES, C. A.; CAFÉ FILHO, A. C.

Estabilidade da resistência de Capsicum spp. ao oídio em telado e casa de vegetação. Fitopatologia Brasileira, Brasília, DF, v. 29, n. 5, p. 519-525, 2004.

PALUDZYSZYN FILHO, E.; SANTOS, P. E. T. Considerações sobre o plantio de Eucalyptus dunnii no estado do Paraná. Colombo: Embrapa Florestas, 2005. (Embrapa Florestas. Comunicado técnico, 141).

POZZA, A. A.; ALVES, E.; POZZA, E. A.; CARVALHO, J. G.; MONTANARI, M.; GUIMARÃES, P. T. G.; SANTOS, D. M. Efeito do silício no controle da cercosporiose em três variedades de cafeeiro. Fitopatologia Brasileira, Brasília, DF, v. 29, p. 185-188, 2001.

REMADE. Eucalyptus benthamii: solução para áreas que ocorrem geadas. Notícias, 16 nov. 2009. Disponível em: <http://www. remade.com.br/br/noticia.php?num $=6610 \&$ title $=$ Eucalyptus $\% 20$ Benthamii $\% 20 \% 96 \% 20$ Solu $\%$ E7\%E3o\%20para $\% 20 \%$ E1reas $\% 20$ que\%20ocorrem\%20geadas>. Acesso em: 23 fev. 2011.

SANTOS, A. F. dos; AUER, C. G.; GRIGOLETTI JUNIOR, A. Doenças do eucalipto no sul do Brasil: identificação e controle. Colombo: Embrapa Florestas. 2001. 20 p. (Embrapa Florestas. Circular técnica, 45).

TRIGUEIRO, R. de M.; GUERRINI, I. A. Uso de biossólido como substrato para produção de mudas de eucalipto. Scientia Forestalis, Piracicaba, SP, n. 64, p. 150-162, 2003. 
